\title{
A percepção de professores de ciências frente aos desafios no processo de ensino e aprendizagem de alunos público alvo da educação especial
}

\section{RESUMO}

Fernanda Welter Adams adamswfernanda@gmail.com orcid.org/0000-0003-4935-5198 Secretaria Municipal de Educaçãă
Catala, Catalão, Goiás, Brasil.
O aluno público alvo da educação especial (PAEE) é, assim como qualquer outro, um sujeito de potencialidades e capaz de se desenvolver, portanto, deve ter oportunidades de se apropriar do conteúdo científico referente às Ciências da Natureza. A deficiência é mais do que algo orgânico, é social e, por isso, pode ser compensada por meio do desenvolvimento de caminhos alternativos promovidos através da prática pedagógica do professor, como por exemplo, a adaptação de conteúdo. Mas, os docentes, comumente, consideram essa prática como um desafio. Outrossim, objetiva-se relatar as percepções de futuros professores de Ciências da Natureza frente aos desafios de ensino para garantir o aprendizado de alunos público alvo da educação especial. Trata-se de uma pesquisa qualitativa, que possui como referencial teórico as concepções de deficiência de Vigotski. Foram sujeitos desta pesquisa 133 graduandos dos dois últimos anos de cursos de licenciatura em Ciências Biológicas, Física e Química, distribuídos em quatro Instituições de Ensino Superior Públicas no Estado de Goiás. Como instrumentos de construção de dados fez-se uso de questionários contendo perguntas tanto abertas como fechadas, respondidas por todos os licenciados participantes e entrevistas semiestruturadas, da qual participaram 19 licenciandos; os dados obtidos foram analisados e estruturados em unidades de significados e posteriormente organizados em categorias emergentes segundo a Análise Textual Discursiva (ATD). Os resultados demostram que a maioria dos licenciandos dos cursos de Ciências Biológicas, Física e Química, percebem como desafios para garantir o aprendizado dos alunos PAEE, o não conhecimento das especificidades dos alunos e a adaptação do conteúdo científico a ser ministrado, sendo estes resultados da falta de uma formação inicial que discuta a educação especial. Essas concepções levam a conclusão de ser necessário a obrigatoriedade da inclusão de uma disciplina específica que aborde desde a história da educação especial, a legislação, as especificidades das deficiências até a prática de ensino com os alunos PAEE, uma vez que tendo conhecimento sobre a deficiência os futuros professores poderão observar a capacidade de aprendizado dos alunos e se sentirão seguros para promovê-la.

PALAVRAS-CHAVE: Ensino de Ciências. Formação inicial. Educação Inclusiva. Deficiência. 


\section{CONSTITUIÇÃO DE DEFICIÊNCIA À LUZ DA PSICOLOGIA HISTÓRICO-CULTURAL}

Conforme a Lei de Diretrizes e Bases da Educação Nacional - LDBEN (BRASIL, 2019, p. 39), a Educação Especial é definida como a "modalidade de Educação escolar, oferecida preferencialmente na rede regular de ensino, para educandos público alvo da educação especial". Apresenta-se que o termo Alunos Público Alvo da Educação Especial (PAEE) refere-se aos alunos com deficiência, transtornos globais do desenvolvimento, altas habilidades e/ou superdotação, conforme definido na "Política Nacional de Educação Especial na Perspectiva da Educação Inclusiva", de 2008 (BRASIL, 2008).

De acordo com os principais documentos legais internacionais e nacionais relacionados aos direitos das pessoas com deficiência, tais como a Declaração de Salamanca (1994), as Diretrizes Nacionais para a Educação Especial na Educação Básica (BRASIL, 2001) e a Política Nacional de Educação Especial na Perspectiva da Educação Inclusiva de 2008 (BRASIL, 2008), a educação especial deve ser oferecida, preferencialmente, na rede regular de ensino, ou seja, a legislação assegura o acesso e a permanência de alunos PAEE em todos os níveis e etapas da educação.

Dessa forma, pode-se observar que as políticas de inclusão na educação escolar brasileira se firmaram a partir da década de 1990. Refletindo sobre tais legislações, especificamente sobre a LDBEN, Baptistone et al. (2017) destacam que para o atendimento às pessoas com deficiência já se indica a necessidade de formação e capacitação docente, o que permite inferir sobre a importância do professor como elemento fundamental para a organização e a prática de um ensino baseado nos princípios inclusivos.

A partir da garantia legal do acesso e permanência do aluno PAEE, faz-se necessário apresentar uma concepção de deficiência, o que é feito com base nos estudos de Vygotsky $(2011,2012)$, que, ao abordar o desenvolvimento da criança com deficiência, afirma que esse processo se dá de forma igualitária para todas as crianças, independentemente da deficiência que a mesma venha a possuir; por sua vez, a criança com deficiência aprende de maneira diferente e por caminhos diferentes da criança "normal".

Lev Semenovich Vigotski ${ }^{1}$ (1896 - 1934), a partir de ideias marxistas, define o homem como um sujeito histórico, cultural e social, propondo então uma nova forma de desenvolvimento levando esses aspectos em consideração. Segundo Adams et al. (2018), esta nova perspectiva possibilitou redirecionar os sentidos em torno da deficiência. Vigotski foi um dos autores que se orientou por esta perspectiva de desenvolvimento. Segundo o psicólogo soviético, a situação em que há uma deficiência deve ser significada como um modo qualitativamente diferenciado de desenvolver-se, isto é, para a apreensão desse fenômeno é preciso levar em consideração seu caráter dinâmico e complexo. Os autores ainda afirmam:

Vigotski é um dos intelectuais preocupados com o desenvolvimento humano, e isso favoreceu as discussões e construções em torno de uma nova concepção de homem e de deficiência. Embora ele não o tenha vivido e participado dos movimentos de inclusão, sua produção e sua concepção de sujeito tem sustentado os argumentos em favor da garantia de direitos a educação especial na atualidade (ADAMS et al., 2018, p. 244). 
Vigotski então, ao discutir sobre a defectologia² ${ }^{2}$ apresenta contribuições para se compreender o processo de desenvolvimento da pessoa com deficiência ou dita "anormal" na época. Segundo ele (1997, p. 37):

Apoiado na teoria materialista dialética sobre o desenvolvimento, Vigotski define a defectologia como ramo do saber acerca da variedade qualitativa do desenvolvimento das crianças anormais, da diversidade de tipos deste desenvolvimento e sobre essa base esboça os principais objetivos teóricos e práticos que enfrentam a defectologia e a escola especial soviética ${ }^{3}$.

A nova concepção de defectologia defendida por Vigotski "está lutando agora por [...] teses básicas que afirmam: [...] a criança cujo desenvolvimento está complicado pela deficiência não é simplesmente uma criança menos desenvolvida que os outros normais, senão desenvolvido de outro modo" (VIGOTSKI, 1997, p. 12). Portanto, o autor entendia a deficiência mais como uma questão social do que biológica.

Nesse seguimento, para o autor, há a deficiência primária e a deficiência secundária. A primeira está ligada à causa orgânica, enquanto a segunda aparece como consequência social da deficiência primária (VIGOTSKI, 1997). Pensar a deficiência, como uma condição incapacitante supõe uma situação concreta na qual há a preponderância do defeito secundário sobre o defeito primário. Este predomínio dos sintomas secundários remete à incapacidade do sujeito de se libertar das amarras biológicas e sociais, de superar, portanto, a deficiência.

Para Vigotski (1997), a deficiência é muito mais uma construção social do que biológica e, por isto, este sujeito é capaz de se constituir como ser humano e de se desenvolver. A pessoa com deficiência, seja qual for e em que nível de comprometimento se apresenta, tal como todas as demais, deve ter oportunidades de se apropriar daquilo que está no plano social, público, levando à sua esfera ou ao seu domínio particular, privado, não só o que se refere aos valores e saberes do convívio cotidiano, mas também o que se refere aos conteúdos científicos; isso é possível a partir do momento em que as potencialidades dessa pessoa são levadas em consideração.

Dessa forma, a deficiência não determina o destino da criança, mas sim as condições sociais que lhes são oferecidas. Góes (2002, p. 99, grifos do autor) ressalta que "não é o déficit em si que traça o destino da criança. Esse 'destino' é construído pelo modo como a deficiência é significada, pelas formas de cuidado e educação recebidas pela criança, enfim, pelas experiências que the são propiciadas".

A partir da ideia de valorização das potencialidades da pessoa com deficiência, Vigotski (1997, p. 80) apresentou o discurso que criticava teorias subjetivistas e idealistas quando se manifestou a favor de uma nova forma de ver o homem pela sua potencialidade e não pela sua deficiência:

O cego seguirá sendo cego e o surdo, surdo, porém deixarão de ser deficientes porque a defectividade é um conceito social, tanto que o defeito é uma sobreposição da cegueira, da surdez e da mudez. A cegueira em si não faz uma criança deficiente, não uma defectividade, isto é, uma deficiência, uma carência, uma enfermidade. Chega a sê-lo somente em certas condições sociais de existência do cego. É um signo da diferença entre a sua conduta e a dos outros. [...]. 
Com base nos escritos de Vigotski e Luria (1996), todos podem aprender e, por isso, desenvolver-se. Todos podem encontrar, em caso de deficiência, meios de desenvolver o talento cultural, isto é, a capacidade de empregar de modo mais eficaz possível as funções que estão íntegras. Quando falta o talento biológico, as mediações culturais contribuem para a construção de um novo edifício: a formação do homem cultural, com todas as compensações possíveis.

Consoante com Vigotski (1997, p. 128), a criança com deficiência é antes de tudo uma criança e somente depois uma criança deficiente. Logo, "não se deve perceber na criança com deficiência apenas o defeito, os gramas de doença, não se notando os quilogramas de saúde que a criança possui."

As ideias da defectologia contribuem para essa nova percepção da pessoa com deficiência como sujeito de potencialidades, atribuindo importância ao ambiente escolar, uma vez que o aprendizado ocorre mediante a inserção do indivíduo em um grupo cultural, promovendo o desenvolvimento das funções psicológicas superiores. Hoje, o que se apresenta é uma proposta fragilizada de inclusão composta de carências no próprio conceito de homem e educação, que continua vendo o homem com deficiência pela sua condição de deficiente, ao invés de vêlo pela sua potencialidade humana.

Assim, cabe à escola e ao professor estarem atentos e disponibilizarem diferentes tipos de recursos pedagógicos para que estas crianças se desenvolvam e tenham acesso ao conhecimento que é proporcionado a todos, permitindo-lhes, com isso, desenvolver um modo de pensar, de memorizar, de abstrair de forma mais complexa, preparando-as para a vida. Para o desenvolvimento do aluno PAEE, Vygotsky (2011) discorre muito claramente sobre a importância dos caminhos alternativos, sendo esses os recursos pedagógicos a serem desenvolvidos pelos professores. $\mathrm{O}$ autor descreve que é através deles que o desenvolvimento da criança acontece, uma vez que esses caminhos são sempre usados quando o caminho direto não dá conta da resposta, quando o mesmo está impedido, ou seja, quando a resposta primeira passa a não ser satisfatória (VYGOTSKY, 2011).

Os conhecimentos já elaborados pelos homens são mediados pelo professor aos estudantes por meio de um planejamento que leve em consideração as potencialidades dos alunos com deficiência, o que permite que os mesmos tenham acesso ao desenvolvimento cultural, já que, "O desenvolvimento cultural é a principal esfera em que é possível compensar a deficiência. Onde não é possível avançar no desenvolvimento orgânico, abre-se um caminho sem limites para o desenvolvimento cultural" (VIGOTSKI, 2011, p. 869).

Vygotski (1997) não nega a existência da deficiência; contudo, enfatiza que o trabalho com ela deve focar em suas consequências sociais, enfim, precisa se situar nos conflitos gestados entre a necessidade de apropriação cultural e a impossibilidade de tal tarefa derivada por uma sociedade pouco sensível às diferenças e adaptada para determinados tipos ideais. As mais sérias deficiências podem ser compensadas a partir de um ensino adequado, e este é proporcionado por uma formação de professores que considere as potencialidades dos alunos com deficiência.

Vigotski e Luria (1996) argumentam que os conteúdos trabalhados pelo mentais evolutivas, decorrentes dos avanços qualitativos no desenvolvimento da 
criança. Assim, a educação escolar precisa contar com professores devidamente instrumentalizados e em condições de criar mediadores específicos para utilizarem técnicas pedagógicas, recursos e métodos especiais que busquem a superação das dificuldades apresentadas pelos alunos.

Destarte, o professor é um dos responsáveis por criar condições, principalmente de permanência (desenvolvimento), para o aluno PAEE no ensino regular. Pensando no professor, diversos pesquisadores, como Chacon (2001), Garcia (2009), Mendes (2011), Pletsch (2009) e Tartuci (2001), observam que é precária a qualificação dos profissionais da educação para lidarem com a educação especial, fator que representa uma barreira para uma educação de qualidade a estes sujeitos.

Barreira essa que somente será transposta por meio de uma formação de professores que os prepare para lidar com as potencialidades desses alunos. Nesse aspecto, Adams $(2018 ; 2020)$ acredita ser de fundamental importância garantir uma formação de professores para lidarem com as potencialidades desse discente. Nesse sentido, Baptistone et al. (2017) destacam que, em se tratando de alunos PAEE, além da formação como professor, é necessário que o docente tenha a formação adequada para tal, aprendendo a respeitar as diferenças e a valorizar as diversidades dos alunos para promover a inclusão educacional de todos os estudantes, em especial, daqueles que possuem uma deficiência.

Observa-se que apesar das diretrizes legais apontarem algumas indicações de como essa formação deve ser feita, não há de fato uma definição política acerca da formação inicial e continuada de professores para atuarem com os alunos público alvo da educação especial.

Dessa forma, acredita-se que uma formação de professores a partir da visão de educação como ato de produzir, direta e intencionalmente, em cada indivíduo singular, a humanidade que é produzida histórica e coletivamente pelo conjunto dos homens (SAVIANI, 2002), bem como de deficiência apresentada pela psicologia histórico-cultural pode contribuir para uma compreensão mais prospectiva da capacidade de aprendizado das pessoas com deficiência.

Corroborando com esse pensamento, Adams (2018; 2020) afirma que olhar para a formação docente através das lentes da psicologia histórico-cultural nos permite enxergar com maior clareza detalhes e nuances fundamentais para o desenvolvimento de um trabalho compromissado com a atuação profissional crítica, reflexiva e sensível. O que implica pensar em um modo de formação que considere as suas experiências sensíveis e a formação em múltiplas linguagens, de modo a propor práticas educativas que auxiliem na apropriação de recursos expressivos e mobilizem a percepção do professor, ser humano em pleno exercício de sua atividade, que se torna mais inteiro e completo a cada experiência vivida e valoriza as vivências e os processos de aprendizado por meio do fazer e do compartilhar.

Nessa perspectiva, o objetivo do presente artigo é relatar as percepções de futuros professores de Ciências da Natureza frente aos desafios para garantir o aprendizado de alunos público alvo da educação especial. 


\section{METODOLOGIA}

O presente artigo faz referência à pesquisa de mestrado intitulada "Docência, Formação de professores e Educação Especial nos Cursos de Ciências da Natureza" que teve como objetivo investigar como a educação dos Alunos Público Alvo da Educação Especial (PAEE) tem sido contemplada na formação inicial de professores de Ciências da Natureza no estado de Goiás. Utilizaram como meio de pesquisa um câmpus de cada Instituição de Ensino Superior Pública do Estado de Goiás, sendo elas, a Universidade Federal de Goiás, a Universidade Estadual de Goiás, o Instituto Federal Goiano e o Instituto Federal de Goiás.

Os sujeitos da pesquisa de mestrado foram tanto coordenadores dos cursos pesquisados, quanto licenciandos do último ano de graduação. Selecionou-se apenas o último ano por se acreditar que esses licenciandos já teriam cursado grande parte da carga horária pedagógica do curso.

Destaca-se que, para este trabalho, são apresentados apenas dados referentes à pesquisa realizada com os licenciandos, para os quais foram aplicados questionários e entrevista semiestruturada. Responderam ao questionário 133 licenciandos, desses, selecionou-se dois licenciandos por curso pesquisado para participarem da entrevista, como investigou-se um total de nove cursos de Ciências da Natureza, dezoito licenciandos foram entrevistados. Salienta-se que tanto o questionário quanto a entrevista foram norteados por roteiros que abordavam o significado da educação especial para os sujeitos, bem como a importância da mesma para a atuação dos licenciandos enquanto futuros professores.

As entrevistas foram gravadas em áudio e depois transcritas com base nas normas elaboradas por Marcuschi (1986), bem como os questionários foram tabulados e organizados em gráficos, com auxílio do programa computacional Excel. Para garantia do anonimato dos sujeitos, criou-se códigos para a sua identificação, adotou-se a letra L para identificar os licenciandos participantes da entrevista, seguida dos números 1, 2, 3...; para determinar a sequência optou-se por utilizar a ordem alfabética dos cursos de Ciências da Natureza e a ordem em que as entrevistas foram realizadas com os participantes, ficando os códigos de L1 a L19. Mas, ao longo do trabalho também são apresentados excertos dos questionários, pois o mesmo possuía questões abertas. Para diferenciar os excertos optou-se pela letra $Q$ para aqueles retirados dos questionários, dessa forma, os códigos de identificação vão de Q1 a Q133.

Isto posto, destaca-se que o presente trabalho possui natureza qualitativa, e se buscou analisar os dados a partir das concepções de deficiência defendidas por Vigotski, por meio da defectologia.

Com relação à pesquisa qualitativa, Martins (2004) afirma que essa é importante porque permite coletar evidências a respeito do tema abordado de maneira criadora e intuitiva, visto que há uma proximidade entre pesquisador e pesquisado, possibilitando a compreensão de crenças e tradições, em um máximo entrelaçar com o objeto em estudo. Segundo Zago (2003), uma pesquisa na perspectiva qualitativa deve permitir a compreensão da realidade homogênea do ambiente de estudo. Condição que se articula à percepção apontada anteriormente sobre pesquisador e participante da pesquisa. 
Bogdan e Biklen (1994, p. 48) afirmam que a pesquisa qualitativa se caracteriza por coletar os dados no "ambiente natural", por meio "do contato direto do pesquisador com a situação estudada", apresentá-los de maneira descritiva e desvendar a "perspectiva dos participantes", "valorizando o processo" de construção de dados. Destaca-se que o ambiente natural do presente estudo são as instituições formadoras de professores no estado de Goiás, sendo que a pesquisadora teve contato direto com os sujeitos da pesquisa no ambiente de estudo deles, a sala de aula. Acredita-se que os pesquisadores devem frequentar os locais de estudo, de forma a conhecer o contexto, sendo que o lócus da pesquisa deve ser compreendido em sua totalidade histórica, social e cultural.

Após a tabulação dos dados passou-se, então, para a etapa de análise dos mesmos, sendo que esses foram organizados em categorias com base na Análise Textual Discursiva (ATD) (MORAES; GALIAZZI, 2007). Com relação à ATD, Moraes (2003) destaca que ela pode ser compreendida como um processo de construção e compreensão dos dados, com base em uma sequência recursiva de três componentes: a desconstrução do corpus, a unitarização, o estabelecimento de relações entre os elementos unitários, a categorização, e o captar do novo emergente em que uma nova compreensão é comunicada e validada.

Dessa forma, os dados da pesquisa, quais sejam, os discursos dos participantes, foram lidos de forma cuidadosa e organizados em unidades de análises, ou seja, os dados foram interpretados e isolados em ideias de sentidos sobre a temática, em seguida, realizou-se o processo de categorização, em que os dados foram agrupados através de sua similaridade, e para finalizar elaborou-se os metatextos, em que foram criados argumentos a partir da interpretação dos dados e do referencial teórico.

Esse processo permitiu a elaboração de diversas categorias, uma delas foi denominada "Depende muito do tipo de necessidade especial do aluno", sendo, portanto, o título da categoria a fala de um dos sujeitos que dá significado à percepção dos futuros professores frente aos desafios do ensino de Ciências da natureza para os alunos PAEE. O que nos leva à relevância dessa categoria, uma vez que garantir o aprendizado desse alunos já se mostra como um desafio, sendo assim, essa temática precisa ser discutida na formação de professores de forma a garantir que eles mudem o olhar frente ao processo de ensino destes sujeitos.

Destaca-se que essa categoria permitiu interligar os dados coletados tanto por meio de questionários, que são apresentados na forma de gráficos, quando das entrevistas, que são apresentadas por meio de excertos, esse cruzamento deu mais significado às discussões realizadas na categoria a ser apresentada.

\section{OS DESAFIOS DE ENSINAR CIÊNCIAS DA NATUREZA A ALUNOS PÚBLICO ALVO DA EDUCAÇÃO ESPECIAL}

A escola tem a função de transmitir o conhecimento historicamente construído pelo homem, desenvolvendo nos alunos a humanidade (SAVIANI, 2001). Dessa forma, o acesso ao conhecimento deve ser garantido a todos os alunos em um mesmo contexto escolar, incluindo os alunos PAEE. Diante disso, o 
potencialidade para fazer uso da mesma e promover o desenvolvimento do estudante.

Vigotski (1997) em seus estudos quebra essa ideia de que a pessoa com deficiência não é capaz de se desenvolver, afirmando que o indivíduo em situação de deficiência se desenvolve como os demais, porém, de maneira diferente. Mas, o que se observa é que os professores consideram um desafio ministrar aulas para turmas que possuem alunos PAEE, pois se sentem despreparados para lidarem com as especificidades de um aluno com deficiência (ADAMS, 2018).

É preciso assegurar aos professores uma formação inicial que discuta a educação especial e as especificidades de cada deficiência, além de oportunizar aos licenciandos a vivência no desenvolvimento de recursos pedagógicos com os alunos PAEE. Corroborando com essa concepção, Benite et al. (2009, p. 4) destacam que "propiciando-lhes situações de análise e reflexão sobre suas próprias condições de trabalho e vivências, permitindo-Ihes estabelecer relações entre a sua ação pedagógica e os pressupostos teóricos que estão subjacentes a ela", será possível ao futuro professor constituir novas posições a respeito das necessidades individuais dos alunos.

Nesse sentido, busca-se relatar as percepções de futuros professores de Ciências da Natureza frente aos desafios de ensino para garantir o aprendizado de alunos público alvo da educação especial.

Frente à temática, alguns pesquisadores da área das Ciências da Natureza apresentam desafios de ministrar aulas para alunos surdos e com deficiência visual, sendo estas as deficiências mais discutidas na área. Com relação à surdez, os autores apresentam como desafio a linguagem química. Este desafio é citado por Pereira et al. (2011) que afirmam que no ensino de Ciências/Química para surdos há termos específicos como átomo, elétron, mol, íon, próton, dentre outros que ainda não fazem parte do grupo de terminologias dos dicionários da Libras, ou seja, não possuem sinais que os identificam, dificultando os sentidos atribuídos pelos alunos relativos aos conceitos ensinados.

Com a falta de sinais que expressem a linguagem química, as particularidades dessa ciência não são abordadas. A linguagem química é uma integração sinérgica de palavras, gráficos, diagramas, figuras, equações e tabelas, dentre outras formas de expressão do conhecimento (PEREIRA et al., 2011). Os autores ainda afirmam que no ensino de Ciências/Química o aluno ouvinte se apropriará dos conceitos pelas informações que recebe do meio, principalmente por intermédio da audição, o que não acontece com o aluno surdo.

Quanto aos deficientes visuais a situação não é diferente. Os livros didáticos são carregados de imagens, gráficos, tabelas e representações específicas da área que são fundamentais para a apropriação do conhecimento pelos alunos. Além dos poucos livros disponíveis em Braille no Brasil, adaptações feitas de forma inadequada "podem se transformar em obstáculos ao acesso as informações vinculadas, com impactos negativos na aprendizagem desses alunos" (PIRES et al., 2007, p. 2).

Os autores supracitados apresentam como desafios a linguagem própria das Ciências da Natureza e a necessidade da leitura de gráficos e imagens para a compreensão dos conteúdos científicos, acreditando que isto coloca os alunos PAEE em desvantagem frente aos demais alunos. Porém, o professor, por meio de 
uma prática pedagógica redirecionada, poderá ajudá-los de maneira objetiva a se apropriarem desses conceitos (BENITE et al., 2009), buscando caminhos alternativos para a aprendizagem desses alunos.

O professor é um dos responsáveis por criar condições, principalmente de permanência do aluno público alvo da educação especial no ensino regular (ADAMS, 2020). Portanto, os professores das instituições que desenvolvem a inclusão devem interessar-se pelo que seu aluno deseja aprender, ou seja, deve levar em conta as potencialidades do mesmo e, a partir delas, elaborar práticas através da mediação para que os alunos desenvolvam a autonomia e a construção de conhecimento. Como já apresentado, por meio das ideias de defectologia, acreditar nas potencialidades dos alunos PAEE é um fator primordial para garantir o processo de ensino e aprendizagem dos mesmos. Aceitá-los, saber escutá-los e valorizar as suas produções ajuda na independência deles. Adotar uma metodologia que venha a estimular a sua participação em sala de aula favorece a sua aprendizagem, mas para que isto ocorra o professor deve estar apto a atender às necessidades do aluno.

Na visão de Pereira et al. (2011, p. 49), é nesse contexto que surge "a importância do papel do professor mediador, representante legítimo da cultura científica a ser ensinada", que, mesmo com o pouco aporte teórico disponível, vislumbra a possibilidade de mudança na própria prática em busca de seu objetivo: o ensino.

Pensando em entender o que os futuros professores veem como desafio para o ensino de Ciências da Natureza com alunos PAEE, elencou-se alguns desafios como: a falta de formação adequada para se trabalhar com a educação especial, a falta de prática com os alunos PAEE, o não conhecimento das especificidades de cada deficiência, trabalhar os conteúdos de ciências de forma a garantir a aprendizagem do aluno PAEE e adaptar o conteúdo ou algum recurso didático. A partir desses, os licenciandos deveriam enumerar de 1 a 5 os desafios apresentados de acordo com a importância, sendo 1 de menor importância e 5 de maior importância. Os resultados estão descritos nos Gráficos 1 (Ciências Biológicas), 2 (Física) e 3 (Química).

Gráfico 1 - Desafios do ensino de Ciências da Natureza frente ao desenvolvimento do aluno público alvo da educação especial no curso de Ciências Biológicas

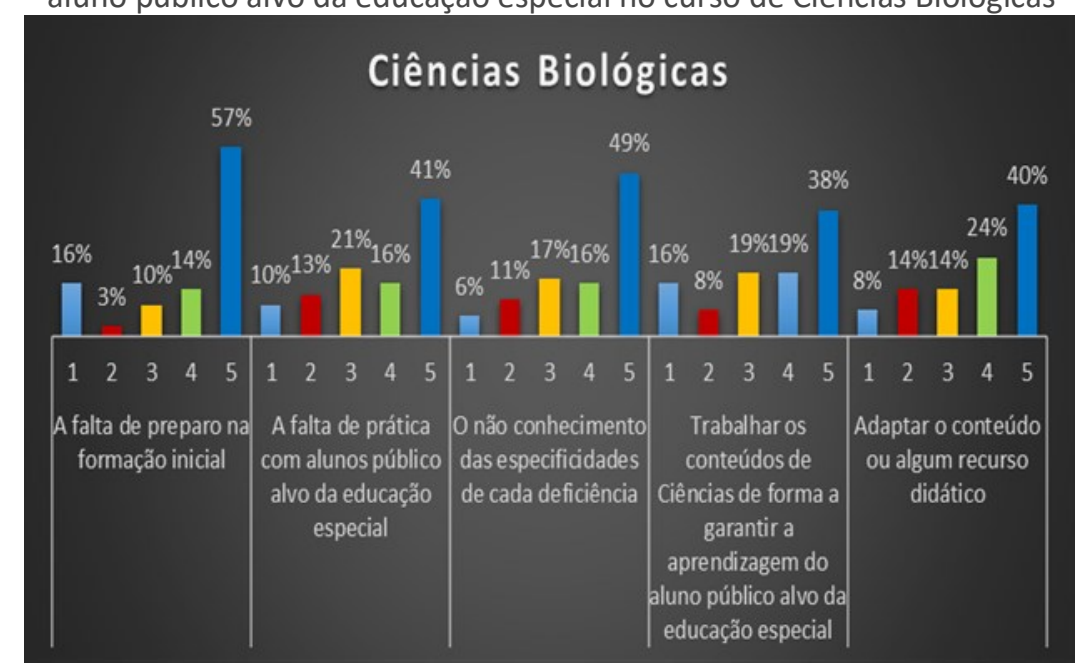

Fonte: ADAMS (2018). 
Gráfico 2 - Desafios do ensino de Ciências da Natureza frente ao desenvolvimento do aluno público alvo da educação especial no curso de Física

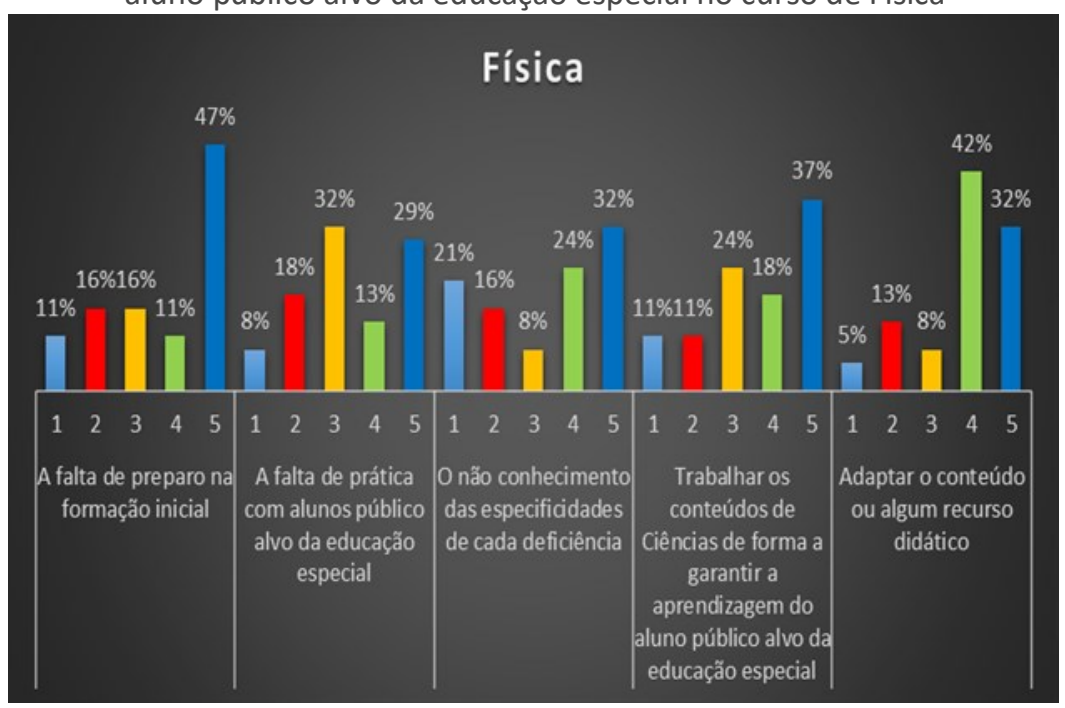

Fonte: ADAMS (2018).

Gráfico 3 - Desafios do ensino de Ciências da Natureza frente ao desenvolvimento do aluno público alvo da educação especial no curso de Química

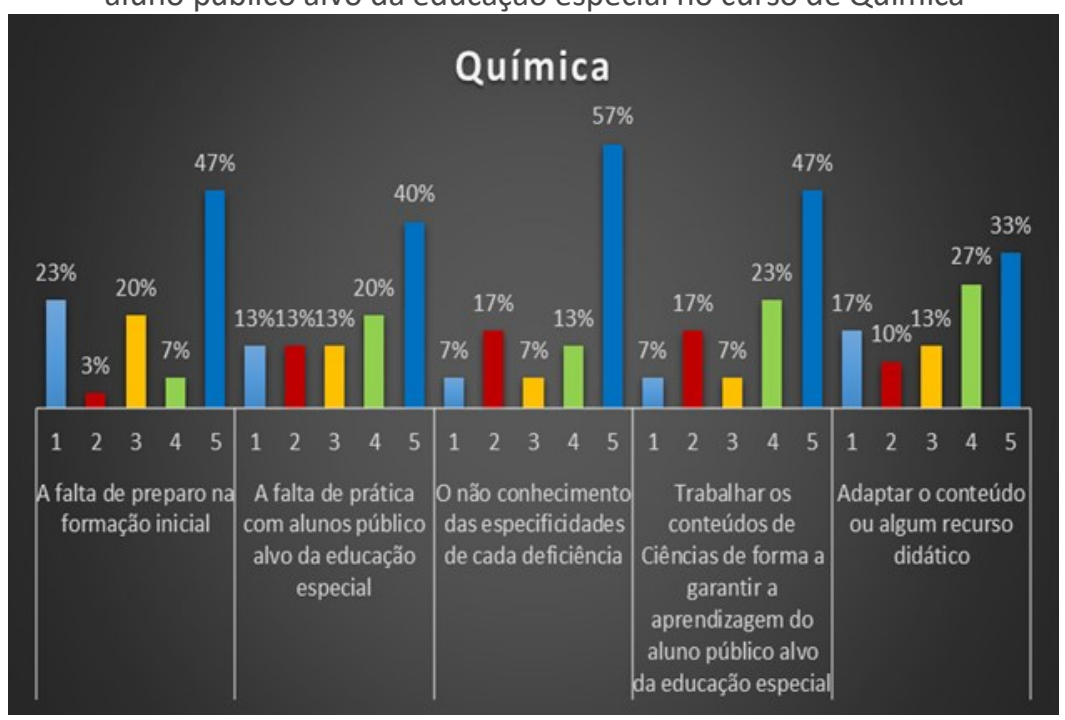

Fonte: ADAMS (2018).

Pode-se observar, pela análise do Gráfico 1, que os licenciandos de Ciências Biológicas consideram todos os desafios elencados pela pesquisadora de maior importância. Mas, dão destaque à falta de preparo na formação inicial, sendo que $57 \%$ dos licenciandos o marcaram. O que dá indícios de que os licenciandos acreditam que para garantir o processo de ensino e aprendizado de alunos PAEE a temática precisa ser discutida em sua formação inicial. Corroborando com os licenciandos, Castanho e Freitas (2005, p. 1) afirmam que "a universidade é um lugar onde os valores e práticas de educação inclusiva precisam ser vivenciados" e, para isso, os licenciandos precisam vivenciar uma formação que vá além do conhecimento científico, de conceitos e organização do trabalho pedagógico. É preciso inserir novas propostas, como a inserção de disciplinas que abordem a discussão da educação especial, de forma a garantir uma preparação sólida nessa 
área. Consequentemente, repensar a formação de professores constitui-se parte fundamental das reformas educacionais, já que são eles que concretizam as ações e formam novos sujeitos (SILVA, 2011).

Diversos licenciandos, representados por 49\%, também citam o não conhecimento das especificidades de cada deficiência como um desafio a ser enfrentado na garantia da aprendizagem dos alunos PAEE. Foi possível observar por meio dos dizeres dos licenciandos dos cursos de Ciências Biológicas que eles se sentem inseguros para planejarem uma aula que inclua o aluno e ainda garanta a aprendizagem desse sem que conheçam as especificidades de aprendizagem de cada deficiência, uma vez que na percepção dos licenciandos o planejamento da aula depende do tipo de deficiência do aluno:

Excerto $1-[\ldots]$ vai depender do tipo de público, no caso de um aluno com deficiência visual ou mental vai ter que diversificar a metodologia, o que serve para um pode não servir para o outro, então o método de ensino vai ter que estar de acordo com público. L4/ Licenciando em Ciências Biológicas.

Excerto 2- Trabalhar o ensino de ciências vai depender de cada tipo de deficiência. Por exemplo, com surdos deveria trabalhar mais a questão do visual, vídeos, por exemplo. L6/ Licenciando em Ciências Biológicas.

Conhecer as especificidades educacionais dos alunos se faz importante para garantir o processo de ensino e aprendizagem, pois assim é possível desenvolver metodologias e recursos didáticos de acordo com as necessidades e potencialidade de cada um. L4, por exemplo, cita a diferença entre uma metodologia para um deficiente visual e um intelectual, apontando a disciplina Química como exemplo, que tem na experimentação uma eficiente metodologia para o ensino desse conhecimento. Todavia, ainda é a observação visual o meio mais usado para coleta e interpretação dos dados, o que dificulta a compreensão dos conteúdos previstos nos experimentos por alunos deficientes visuais (BENITE et al., 2017). Dessa forma, uma descrição do processo ocorrido ou o uso de Tecnologia Assitivas facilitariam o aprendizado do aluno com deficiência visual, já com o aluno com deficiência intelectual o planejamento precisa ir além da descrição, é preciso que ocorra uma adaptação do currículo.

Em posse de saberes específicos sobre as especificidades educacionais desses alunos os professores terão a compreensão de que eles podem aprender desde que sejam atendidas as suas especificidades que se manifestam quando se deparam com o currículo, os recursos, as sequências e os ritmos de aprendizagem, que são habitualmente trabalhados no ensino regular (NOZI, 2013).

Para Vigotski (1997), qualquer deficiência modifica a relação do homem com o mundo e influencia as relações com as pessoas, ou seja, a limitação orgânica se mostra como uma "anormalidade social da conduta". Contudo, não é a diferença biológica o principal fator que implica em desenvolvimento limitado ou em não desenvolvimento da pessoa com deficiência, afinal, essa é tida sob diferentes modos e valoração em conformidade com as especificidades de cada sociedade.

O homem é um ser social, embora toda a saga da formação humana ontogenética se paute num equipamento biológico inicial, a direção do desenvolvimento é a superação desse pelo reequipamento cultural, no caso da pessoa com deficiência, o percurso segue a mesma direção, isto é, os seus olhos, 
as suas cordas vocais, as suas mãos, enfim, todo o seu corpo deve ser formado socialmente (COELHO; BARROCO; SIERRA, 2011).

No excerto 3, apresentado a seguir, observa-se ainda que um licenciando destaca que na formação inicial deveria haver uma disciplina que discutisse as especificidades de cada deficiência de modo a contribuir com a prática do futuro professor:

Excerto 3 - Acho que uma disciplina que abrangesse todas as deficiências, facilitaria para o professor pensar um método para trabalhar a biologia com o aluno dentro da sala de aula, o que seria bastante interessante. L4/Licenciando da Ciências Biológicas.

Acredita-se que, além de trabalhar com as especificidades de cada deficiência, uma disciplina que discuta a educação especial deve levar os licenciandos a refletirem que o problema não é a deficiência, mas as consequências da deficiência na integração de uma pessoa na vida em sociedade. Assim, essas consequências devem ser o foco da formação de professores, como afirma Vigotski (1997, p. 4344):

\footnotetext{
Quando temos diante de nós um cego, como objeto da educação, temos que ver não tanto com a cegueira por si mesma, como com os conflitos que se tornam presentes a criança cega ao entrar na vida, quando tem lugar a substituição dos sistemas que determinam todas as funções da conduta social da criança. E por isso me parece que, do ponto de vista pedagógico, a educação da criança se limita a retificar totalmente estes desajustes sociais. [...] A tarefa da educação consiste em incorporar na criança a vida e criar a compensação do seu defeito físico. A tarefa se reduz a que a alteração do laço social com a vida seja feito por alguma outra via.
}

Ao se analisar os resultados do Gráfico 2, pode-se observar que os licenciandos de Física também destacam a falta de preparação na formação inicial (47\%) e a falta de prática com os alunos público alvo da educação especial (32\%) como de média importância. A partir dos desafios destacados para a aprendizagem dos alunos PAEE pelos licenciandos, defende-se mais uma vez a necessidade de se inserir a discussão sobre a educação especial com mais frequência nos cursos de formação inicial de professores. Basso (2015), em sua tese de doutorado sobre a mesma temática, também apresenta como resultados que os futuros professores de Ciências compreendem a formação inicial como um desafio para o ensino dos alunos PAEE, e discute ser necessário que todas as disciplinas da área pedagógica de ensino abordem a temática, permitindo então que o professor auxilie estes alunos na garantia de seu direito a uma educação de qualidade.

Os licenciandos ainda elencam como desafio para a aprendizagem dos alunos PAEE a adaptação do conteúdo ou de algum recurso didático, com $42 \%$ no número quatro (4), que representa quase de maior importância. O currículo adaptado implica compreender situações diferenciadas, maneiras diversificadas de apresentar conteúdos que facilitem a compreensão dos alunos. Mas, destaca-se que a adaptação não é escolher o conteúdo que o aluno PAEE irá estudar, e sim facilitar a sua compreensão por meio da potencialidade do aluno, garantindo condições que Ihe são indispensáveis para acesso ao conhecimento disponível, corroborando com esse entendimento, Costa (2009) afirma que nunca será permitida a adaptação do currículo com a intenção de selecionar quais conteúdos 
o aprendente com deficiência terá condições ou não de aprender. Seria um equívoco pensar adaptação de currículo neste formato.

Ainda com relação a se trabalhar com o conteúdo de Ciências da Natureza de forma a garantir a aprendizagem dos alunos PAEE:

Excerto 4- Com a deficiência, vai ser muito mais difícil ensinar certos conteúdos, por exemplo, ao se abordar a física ondulatória, luzes ópticas, como que se ensina luz para um menino com deficiência visual de forma que ele aprenda [...] a gente elabora experimentos para fugir do tradicional, em mecânica que é muito teórica, eu não sei como que inclui esse aluno para participar da atividade e aprender. L9/Licenciando da Física

No excerto 4, o licenciando demonstra sua preocupação com o processo de ensino e aprendizagem do aluno PAEE por meio dos dizeres: "Eu não sei como que inclui esse aluno para participar da atividade e aprender" isto porque o mesmo afirma "não saber" como planejar uma aula levando em consideração as especificidades destes alunos. Estes dizeres demonstram mais uma vez que os desafios percebidos pelos licenciandos para o trabalho com a educação especial são reflexo da não discussão sobre a temática na sua formação inicial.

A preocupação do licenciando é de relevância frente à temática, pois, como descrito por Vigostki, o aluno com deficiência é capaz de aprender, mas, para tanto, ele precisa de caminhos alternativos, que são propostos pelos professores por meio de metodologias e recursos didáticos. Góes (2011), ao refletir sobre o exposto, discute que a falta de proposições de caminhos alternativos pode tornar frágil a qualidade da educação para o aluno PAEE, haja vista que a ausência de um trabalho pedagógico que atenda às reais necessidades do aluno significa deixá-lo à margem do processo de ensino que por si só não vai garantir a aprendizagem do mesmo.

Ao analisar o Gráfico 3, observa-se que os resultados dos cursos de Química investigados se assemelham aos dos cursos de Ciências Biológicas, ou seja, os licenciandos de Química acreditam que todos os desafios apresentados são de grande importância para garantirem a aprendizagem de Ciências aos alunos PAEE. Mas, durante as entrevistas, ficou evidente que não conhecer as especificidades das deficiências é uma angústia para os futuros professores de Química:

\footnotetext{
Excerto 5 - Depende muito do tipo de necessidade especial do aluno, por exemplo, como trabalhar com um aluno se ele é cego é complexo, você teria que usar o tato e os ouvidos dele. E em Química quando fala dos modelos atômicos que é visual e não dá para usar os outros sentidos, com fazer isso? É complexo. L14/Licenciando da Química.
}

Excerto 6 - Acho que a forma como trabalhar os conteúdos de Química vai depender da deficiência do aluno. L16/Licenciando da Química.

Além da especificidade de cada deficiência, observa-se no excerto 5 a preocupação do licenciando com a parte visual dos conteúdos científicos a serem ministrados. L14 cita o conteúdo de modelos atômicos, em que, segundo ele, a visão é fundamental para a sua compreensão. A partir do conteúdo citado por L14, Razuck e Guimarães (2014) desenvolveram protótipos para o seu ensino, por exemplo, para o Modelo de Thompson, descrito como uma esfera incrustada de elétrons, eles utilizaram um balão inflável, preenchido com maisena 
(representando a parte positiva) e miçangas palpáveis (representando os elétrons). Quando manuseado, é possível sentir as miçangas internas, que representam os elétrons. Também foi utilizada uma esfera feita de massa de cimento, com pingos de parafina em seu exterior, para representar os elétrons que também poderiam localizar-se na extremidade do "átomo".

O uso desses protótipos permitiu que os alunos PAEE pudessem manusear e sentir os materiais, facilitando assim a imaginação de tais modelos. Os autores afirmam ainda que com o uso de materiais adaptados verifica-se que quando são oferecidas ao aluno cego vias de ensino que exploram o visual, seu desempenho é igual ao de um aluno sem deficiência $O$ manuseio de um material adaptado possibilita ao cego visualizar através do tato, funcionando como um referencial para que possa construir no imaginário uma imagem, o que exalta a necessidade de o professor levar para a sala de aula recursos didáticos concretos (RAZUCK; GUIMARÃES, 2014).

Entende-se ser fundamental discutir na formação de professores de Ciências da Natureza sobre materiais didáticos adaptados com o intuito de facilitar a compreensão dos alunos PAEE, permitindo a eles a apropriação do conhecimento científico como forma de superar a angústia citada pelo licenciando, uma vez que, ao utilizar tais recursos didáticos, o professor propõe uma metodologia diferenciada. Destaca-se, no entanto, que além de levar um material adaptado, o professor precisa promover situações de aprendizagem, como de autonomia para que o aluno se desenvolva. Sobre isso, Razuck e Guimarães (2014) explicam que deve haver uma exploração sobre o material, as características que o representam e as limitações. Mas, vale ressaltar a necessidade de deixar que os alunos cheguem a conclusões, dando espaço para que explorem suas ideias sobre o assunto. No diálogo, é importante fazer com que o aluno verbalize o que está compreendendo sobre o material, suas percepções pessoais. A verbalização o ajuda a organizar as informações, o que faz com que intensifique a apropriação do conhecimento, considerando que aprender é dialogar com a palavra do outro (RAZUCK; GUIMARÃES, 2014).

Com relação ao uso de recursos didáticos e metodologias diversificadas no processo de ensino e aprendizagem dos alunos PAEE, a maioria dos licenciandos, quase $100 \%$, acredita que os conteúdos de Ciências da Natureza devem ser ensinados aos alunos através desses recursos e metodologias, como pode ser observado nos excetos a seguir:

Excerto 7- A Biologia é muito visual, então eu acho que deveria ser usado metodologias para esclarecer isso, para alunos com deficiência visualizarem melhor, trabalhar como os outros sentidos. L5/Licenciando de Ciências Biológicas.

Excerto 8- Acho que tem que ser de forma diferenciada (a aula ministrada) não pode ser da mesma forma que para os outros alunos [...] com uma prática diferente eles conseguirão assimilar melhor o conteúdo. L10/Licenciando da Física. desenvolver atividades, como os jogos, eles tem sua função dentro do sistema educativo [...] eles podem ser usado com os diferentes graus e diferentes tipos de deficiência [...] pois no jogo o aluno tem o apoio de uma outra pessoa da sala de aula. L13/Licenciando da Química. 
Os dizeres dos licenciandos corroboram com as pesquisas na área de Ciências da Natureza que em sua maioria são pautadas na elaboração de recursos didáticos e metodologias diversificadas. Oliveira et al. (2012), por exemplo, apresentam sugestões de estratégias metodológicas para serem desenvolvidas com alunos surdos, Pires (2010) discute a elaboração de materiais adaptados para o ensino de Ciências para alunos com deficiência visual, Mól et al. (2004; 2005) trabalham com a produção de materiais didáticos para o ensino de Química com alunos com deficiência visual, entre vários outros autores.

Mas, destaca-se que elaborar estes recursos didáticos e metodologias diversificadas não é tarefa fácil, principalmente quando o professor não possui uma formação de qualidade que o prepare para isso. Glat e Pletsch (2004) citam que o grande desafio posto para as universidades é formar educadores que não sejam apenas instrumentos de transmissão de conhecimentos, mas, sobretudo, formadores de novas atitudes frente à diversidade humana e que esses devem ser preparados para construir estratégias de ensino e adaptar atividades e conteúdos não só para os alunos com deficiência, mas para todos os integrantes de sua classe. As autoras corroboram com a ideia de que a Universidade deve garantir aos futuros professores a discussão tanto sobre a educação especial de forma geral como sobre as maneiras de adaptar os conteúdos para garantir o desenvolvimento dos alunos PAEE.

Com relação à preparação para a realização de adaptações, observou-se que a maioria dos licenciandos dos cursos pesquisados, sendo $62 \%$ do curso de Ciências Biológicas, $81 \%$ de Física e $67 \%$ e Química, acredita que a sua formação não os prepara para isso e poucos licenciandos tiveram o contato ou elaboraram algum material adaptado para estes alunos:

\footnotetext{
Excerto 10 - Em uma das aulas a gente fez uma simulação, com os colegas da turma mesmo; produzimos um jogo do conteúdo de cinética química e uma apostila. Primeiro seria dado o conteúdo e depois seria aplicado o jogo para avaliar [...] Foi elaborado para ai deficiência intelectual, mas não chegamos a aplicar na prática. L19/Licenciando da Química.
}

Excerto 11- Cheguei a ver umas moléculas orgânicas, e em um congresso que fui eu vi modelos atômicos, por exemplo, o de Rutherford onde os elétrons estão na eletrosfera, girando ao redor do núcleo L18/Licenciando da Química.

No excerto 10 vê-se que o licenciando chegou a elaborar um jogo didático sobre o conteúdo de cinética química para alunos com deficiência intelectual, mas não desenvolveu o recurso com os alunos e sim dentro da Universidade. Observase que este momento não deixa de representar um aprendizado ao futuro professor, pois levou o mesmo a pesquisar e a refletir sobre como desenvolver uma aula e um recurso didático para uma turma com a presença de um aluno com deficiência intelectual. Mas, defende-se que se faz necessário que os licenciandos vivenciem essas adaptações na prática. Adams (2018) explica sobre a necessidade dos licenciandos terem momentos de vivência com os alunos PAEE durante os estágios.

Por meio da análise do excerto 11, pode-se verificar que o licenciando teve contato com materiais adaptados em um congresso, a experiência citada por ele mostra que alguns eventos da área de ensino de Ciências têm se preocupado com a discussão sobre a educação especial. Observa-se que estes eventos apresentam 
estes materiais adaptados aos professores por meio de minicursos e apresentações de trabalhos, promovendo assim a discussão de que é possível garantir o processo de ensino e aprendizagem dos alunos PAEE. Defende-se que os eventos e congressos são excelentes ferramentas de formação, principalmente por oportunizarem a troca de experiências entre professores. Mas, a discussão que ocorre nos mesmos não é o suficiente para garantir uma formação de qualidade, é preciso que ocorram reflexões mais aprofundadas frente ao assunto por meio de disciplinas específicas na grande curricular dos cursos de formação de professores.

Tais disciplinas, além de discutirem a elaboração de metodologias e recursos didáticos diferenciados para o ensino de Ciências, devem debater sobre como ocorre o desenvolvimento do aluno PAEE e as especificidades das deficiências. Nesse sentido, Facci (2004) acredita que a forma como professor compreende o desenvolvimento do psiquismo, a educação e o processo de ensino e aprendizagem guiará toda a sua intervenção no contexto escolar. Zucco et al. (2009) corroboram afirmando que saber identificar o nível de desenvolvimento cognitivo dos estudantes redunda em saber adequar o ensino, as metodologias e os materiais às diferentes realidades encontradas.

De extrema importância nesse processo de desafiar o aluno, de conhecer o seu desenvolvimento e de promover a apropriação do conhecimento é a mediação do professor, uma vez que é o docente quem garante ao aluno a apropriação dos elementos culturais e do conhecimento científico, pois é o professor que desafia o aluno para além de seu desenvolvimento real com a proposição de situações promotoras de desenvolvimento (VYGOTSKI, 2001).

Nesse seguimento, Silva e Schnetzler (2006) expressam que os modos de mediação determinam como o professor se vê como tal, sua função social e seu trabalho educativo. Em particular, expressam: como ele aborda os diversos temas de sua disciplina; as estratégias que utiliza para promover a elaboração/reelaboração de conceitos científicos; as interações que estabelece com seus alunos; as concepções de ensino, aprendizagem e de conhecimento químico que orientam sua prática; as relações que estabelece entre os conteúdos do seu ensino e temas da vida social e cotidiana dos alunos, aspectos estes que rejeitam articulações entre as dimensões teórica e prática da docência.

Pode-se observar que muitos são os desafios para garantir o processo de ensino e aprendizagem de Ciências aos alunos PAEE, como a falta de formação inicial, o não conhecimento das especificidades dos alunos e a adaptação do conteúdo a ser ministrado. Vê-se que a forma de superar tais desafios é por meio da inclusão da discussão sobre a educação especial nos cursos de formação inicial, entre os futuros professores e os que já atuam por meio da formação continuada.

Vitaliano e Manzini (2010) afirmam que inserir nos cursos de formação de professores discussões a respeito das características das deficiências pode auxiliar o docente a construir concepções mais positivas acerca do aprendizado dos estudantes com deficiência e a "identificar os procedimentos de ensino que podem ser comuns a todos os alunos, bem como aqueles que realmente necessitam ser diferentes" (VITALIANO; MANZINI, 2010, p. 70).

Mas, acredita-se que a discussão sobre a deficiência deve ser pautada em um referencial teórico que garanta aos licenciandos a visão dos alunos PAEE como 
possuidores de potencialidades e capazes de aprender, para tanto, sugere-se as ideias de defectologia apresentadas neste artigo.

\section{CONSIDERAÇÕES FINAIS}

Por meio do entrecruzamento das percepções dos licenciados através dos dados dos instrumentos de pesquisa utilizados, pode-se observar que eles destacam como desafios para garantir o processo de ensino e aprendizagem de ciências aos alunos PAEE: a falta de formação inicial, o não conhecimento das especificidades dos alunos e a adaptação do conteúdo a ser ministrado.

Portanto, a percepção dos sujeitos leva a crer que se torna urgente garantir ao futuro professor uma formação inicial que proporcione tanto a discussão teórica sobre a deficiência a partir da ideias de defectologia apresentada por Vigotski, considerando as potencialidades desses alunos, quanto a prática, de modo que os futuros professores desenvolvam adaptações dos conteúdos científicos com os alunos, vivenciando assim o processo de ensino e aprendizagem dos mesmos e reconhecendo sua capacidade de se desenvolver.

Sabe-se que garantir o desenvolvimento do licenciando como humano e como profissional preocupado em desenvolver as potencialidades de todos os seus alunos se dá através de conhecimentos produzidos acerca da educação, da vivência e da interação dele com os alunos com e sem deficiência.

Sendo assim, defende-se a necessidade e a obrigatoriedade da inserção de uma disciplina que discuta a educação especial em todos os cursos de licenciatura e que aborde a história da educação especial, a legislação, as especificidades de cada deficiência e as práticas de ensino com alunos PAEE, como forma de garantir que o futuro professor chegue à escola preparado para garantir o processo de ensino e aprendizagem dos alunos. 


\title{
Science teachers' perceptions regard the challenges of teaching and learning process of inclusive education students
}

\begin{abstract}
The student with disabilities or aluno público alvo da educação especial (PAEE), as any other student, have potentiality and capability to develop yourself. Consequently, they must have opportunities to learn the scientific content related to the Natural Sciences. Besides the organic disabilities, the social prejudice against people with disability seems to be the major obstacle to deal with. To tackle these problem teachers need to come up with alternative paths to adapt this content, but generally, they look at it as a huge challenge. The objective of this article is to report the perceptions of future teachers of Natural Sciences regard the teaching challenges of inclusive education. A qualitative research method is applied in this study, which has Vygotsky's conceptions of disability as a theoretical reference. The subjects of this research were 133 undergraduate students. Most of them the lack at most two years to graduate. They are students of Biological Sciences, Physics and Chemistry, from four Public Higher Education Institutions in the State of Goiás. We used semi-structured questionnaires to gather research data from 19 individuals who participated of this research. They answered all the open and closed questions. We group the data in structured units of meaning, and then we merge it in categories that emerged according to Discursive Textual Analysis (DTA). The results revealed that most graduates of the Biological Sciences, Physics and Chemistry courses perceive challenges to guarantee the learning of PAEE students. Furthermore, we note that they do not have any knowledge of the specificities of the students with disabilities and do not have a clue about how to adapt their scientific content to these students. It mean that their courses need to discuss more about inclusive education. We conclude that these science teacher's courses should include a specific subject about inclusive education. In other words, to improve their teach practice and consequently include their students with disabilities, the students need to know about the history of special education, legislation and the specificities of disabilities. With this background, future teachers will be more confident and able to observe the students' learning capacity.
\end{abstract}

KEYWORDS: Science teaching. Initial formation. Inclusive education. Disability. 


\section{NOTAS}

1. O nome de Vigotki tem sido grafado de diversas formas na literatura. Optou-se na escrita deste artigo por esta, a não ser em caso de citações diretas ou referências, em que a grafia adotada pelo autor será mantida.

2. Este termo foi utilizado por Vigostski e outros autores referindo-se à área de estudos teóricos e práticos relativos à preocupação quanto à educação de pessoas com deficiência, ao que se conhece hoje como educação especial. Não há uma tradução literal em português, assim, será mantida a tradução do espanhol.

3. As citações desta obra foram traduzidas do espanhol pelos autores, e conserva alguns termos originais utilizados por Vigotski presentes na obra lida que não fazem parte da nomenclatura mais atual.

\section{REFERÊNCIAS}

ADAMS, F. W.; NEVES, P. F. A. C.; SILVA, B. R. Pensar a deficiência a partir das contribuições da abordagem histórico-cultural: o direito a educação especial. In: SILVA, A. A.; KUNZ, S. A. S (Ogs.) Direitos Humanos e Educação. Uberlândia: Culturatrix, 2018.

ADAMS, F. W. Docência, Formação de Professores e Educação Especial nos Cursos de Ciências da Natureza. 2018. Dissertação (Mestrado em Educação), Universidade Federal de Goiás, Catalão, 2018.

ADAMS, F. W. Abordagem Histórico-Cultural: um olhar para a formação de professores e a educação especial. 1 ed. Curitiba: Editora Appris, 2020.

BAPTISTONE, G. P.; NETO, I. A. M.; TOYAMA, K. S. F.; PRAIS, F. L. S. A Inclusão Do aluno cego na educação superior: percepções de professores de um curso de licenciatura em Química. ACTIO, Curitiba, v. 2, n. 1, p. 98-121, jan./jul. 2017.

BASSO, S. P. S. Cursos De Licenciatura Na Área De Ciências: A Temática Inclusão Escolar De Alunos Com Necessidades Educacionais Especiais. Tese (Doutorado em Educação para a Ciência), Universidade Estadual Paulista "Júlio de Mesquita Filho", Bauru, 2015.

BENITE, A. M. C.; PEREIRA, L. L. S.; BENITE, C. R. M.; PROCÓPIO, M. V. R. e FRIEDRICH, M. Formação de professores de ciências em rede social. RBPEC, v. 9, n. 3, 2009.

BENITE, C.R.M.; BENITE, A.M.C.; BONOMO; F.A.F.; VARGAS, G.N.; ARAÚJO, R.J.S.; ALVES, D.R. Observação inclusiva: $O$ uso da tecnologia assistiva na experimentação no ensino de Química, v.12, n. 2, p. 94-103, 2017.

BOGDAN, R. C.; BIKLEN, S. K. Investigação Qualitativa em Educação - uma introdução à teoria e aos métodos. Tradução: Marie João Alvarez, Sara Bahia dos Santos e Telmo Mourinho Baptista. Portugal: Porto Editora, 1994. 
BRASIL. Lei de Diretrizes e Bases da Educação Nacional - Lei no 9.394/96. Brasília, 2017.

BRASIL. Resolução CNE/CEB no 2, de 1 de setembro de 2001. Institui Diretrizes Nacionais Para a Educação Especial na Educação Básica. Brasília, 2001.

BRASIL. Política Nacional de Educação Especial na Perspectiva da Educação Inclusiva. MEC/SEESP. 2008.

CASTANHO, D. M.; FREITAS S. N. Inclusão e prática docente no ensino superior. Revista Educação Especial. Santa Maria, n. 27, 2005. Disponível em: http:// www.ufsm.br/ ce/revista/ceesp/2006/01/a6.htm. Acesso em: 18 jun. 2020.

CHACON, M. C. M. Formação de recursos humanos em Educação Especial: resposta das universidades brasileiras à portaria no. 1. 793 de 27/12/1994. 2001. Tese (Doutorado) - Universidade Estadual paulista Júlio de Mesquita Filho, Campus Marilia, Marilia, 2001.

COELHO, T. P. C.; BARROCO, S. M. S.; SIERRA, M. A. B. O conceito de compensação em L. S. Vigotski e suas implicações para educação de pessoas cegas. In: X CONPE Congresso Nacional de Psicologia Escolar e Educacional, Anais $[\ldots], 2011$.

COSTA, V. F. Inclusão, sem risco de excluir. Olinda, PE: Babecco, 2009.

FACCI, M. G. D. A periodização do desenvolvimento psicológico individual na perspectiva de Leontiev, Elkonin e Vigotski. Cad. Cedes, Campinas, v. 24, n. 62, p. 64-81, abril 2004.

GARCIA, R. L. A avaliação e suas implicações no fracasso/sucesso. In: ESTEBAN, M. T. (Org.). Avaliação: uma prática em busca de novos sentidos. Rio de Janeiro: DP\&A, 2009. p. 29-49.

GLAT, R.; PLETSCH, M. D. O papel da Universidade frente às políticas públicas para educação inclusiva. Benjamin Constant (Rio de Janeiro), Rio de Janeiro - RJ, v. 10, n. 29, p. 3-8, 2004.

GÓES, M. C. A construção de conhecimentos e o conceito de zona de desenvolvimento proximal. In: MORTIMER, E.F.; SMOLKA, A.L.B. (Org.). Linguagem, cultura e cognição: reflexões para o ensino e a sala de aula. Belo Horizonte: Autêntica, 2001. p. 77-88.

GÓES, M. C. Relações entre desenvolvimento humano, deficiência e educação: contribuições da abordagem histórico-cultural. In: OLIVEIRA, M. K.; REGO, T. C.; SOUZA, D. T. Psicologia, educação e temáticas da vida contemporânea. São Paulo: Moderna, 2002.

MARCUSCHI, L. A. Análise da conversação. São Paulo: Ática, 1986. (Série Princípios). 
MARTINS, H. H. T. D. Metodologia qualitativa de pesquisa. Educação e Pesquisa, São Paulo, v. 30, n. 2, p. 289-300, maio/ago. 2004.

MENDES, E. G. Inclusão escolar pela via da colaboração entre educação especial e educação regular. Educar em Revista, Curitiba, n. 41, p. 81-93, jul./set. 2011. Editora UFPR.

MORAES, R. Uma Tempestade de Luz: a compreensão possibilitada pela análise textual discursiva. Ciência \& Educação, São Paulo, v. 9, n. 2, p. 191-211, 2003.

MORAES, R.; GALIAZZI, M. C. Análise Textual Discursiva. Ijuí/RS: Editora Unijuí, 2007.

MOL, G. S. et al. Elaboração de Recursos Didáticos para o Ensino de Química para cegos. In: XII ENCONTRO NACIONAL DE ENSINO DE QUÍMICA. Anais [...]. Salvador, BA, Brasil, 2004.

MOL, G. S. et al. Ensinando e experimentando Química com alunos deficientes visuais. In: 28a REUNIÃO ANUAL DA SOCIEDADE BRASILEIRA DE QUÍMICA, Anais [...], Poços de Caldas, MG, Brasil, 2005.

NOZI, G. S. Análise dos saberes docentes recomendados pela produção acadêmica para a inclusão escolar de alunos com necessidades educacionais especiais. 2013. Dissertação (Mestrado em Educação) - Universidade Estadual de Londrina, 2013.

OLIVEIRA, W. D.; MELO, A. C. C.; BENITE, A. M. C. Ensino de Ciências para deficientes auditivos: um estudo sobre a produção de narrativas em classes regulares inclusivas. Revista Electrónica de investigación em educación em Ciencias, v. 7, n. 1, p. 01-09, 2012.

PEREIRA, L. L. S.; BENITE, C. R. M.; BENITE, A. M. C. Aula de química e surdez: sobre interações pedagógicas mediadas pela visão. QNEsc, v.33, n.1, 2011.

PLETSCH, M. D. A formação de professores para a educação inclusiva: legislação, diretrizes políticas e resultados de pesquisas. Rev. Educ., Curitiba, n. 33, Editora UFPR, 2009.

PIRES, R.; RAPOSO, P. N.; MÓL, G. S. Adaptação de um livro didático de Química para alunos com deficiência visual. Anais do VI ENPEC, Florianópolis: 2007.

PIRES, R. F. M. Proposta De Guia Para Apoiar a Prática Pedagógica de Professores de Química em sala Inclusiva com Alunos que Apresentam Deficiência Visual. 2010. Dissertação (Mestrado Profissional em Ensino de Ciências) - Universidade Federal de Brasília, Brasília, 2010.

RAZUCK, R. C. S. R.; GUIMARÃES, L. B. O desafio de ensinar modelos atômicos a alunos cegos e o processo de formação de professores. Revista Educação Especial, v. 27, n. 48, p. 141-154, jan./abr. 2014. 
SAVIANI, D. Escola e democracia. Edição comemorativa. Campinas: Autores Associados, 2001.

SILVA, L. H.; SCHNETZLER, R. P. A mediação pedagógica em uma disciplina científica como referência formativa para a docência de futuros professores de Biologia. Ciência \& Educação, v. 12, p. 57-72, 2006.

SILVA. K. A. C. P. C. A formação de professores na perspectiva críticoemancipadora. Linhas Críticas, vol. 17, n. 32, p. 13-31, abr. 2011.

TARTUCI, D. Experiência Escolar de Surdos no Ensino Regular: condições de interação e construção de conhecimento. 2001. 182f. Dissertação (Mestrado em Educação) - Universidade Metodista de Piracicaba, 2001.

UNESCO. Declaração de Salamanca: sobre princípios, política e prática em educação especial, de 10 de junho de 1994.

VIGOTSKY, L. S; LURIA, A. R. Estudos sobre a história do comportamento: o macaco, o primata e a criança. Porto Alegre: Artmed, 1996.

VIGOTSKY, L. S. Obras escogidas: fundamentos de defectologia. Madrid: Visor, 1997. v. 5.

VIGOTSKY, L. S. Psicologia pedagógica: um curso breve. Buenos Aires: AIQUE, 2001.

VIGOTSKY, L. S. A Defectologia e o estudo do desenvolvimento e da educação da criança anormal. Educação e Pesquisa, São Paulo, v. 37, n. 4, p. 861-870, dez. 2011.

VIGOTSKY, L. S. Obras Escogidas - V: Fundamentos de Defectologia. Machado Grupo de distribucion, S. L. 2012.

VITALIANO, C.R.V.; MANZINI, E.J.A Formação Inicial de Professores para a Inclusão de Alunos com Necessidades Educacionais Especiais. In: VITALIANO, C. R. Formação de professor para a inclusão de alunos com necessidades educacionais especiais. Londrina: Eduel, 2010. p. 50-112.

ZAGO, Nadir et all. (Org.). Itinerários de Pesquisa - perspectivas qualitativas em Sociologia da Educação. Rio de Janeiro: DP\&A, 2003. 
Recebido: 18 jan. 2020

Aprovado: 27 set. 2020

DOI: 10.3895/actio.v5n3.11519

Como citar:

ADAMS, F. W. A percepção de professores de Ciências frente aos desafios no processo de ensino e aprendizagem de alunos público alvo da educação especial. ACTIO, Curitiba, v. 5, n. 3, p. 1-23, set./dez. 2020. Disponível em: <https://periodicos.utfpr.edu.br/actio>. Acesso em: XXX

Correspondência:

Fernanda Welter Adams

Rua 2004, n. 80, Bairro Paineiras, Catalão, Goiás, Brasil.

Direito autoral: Este artigo está licenciado sob os termos da Licença Creative Commons-Atribuição 4.0 Internacional. 